\title{
$\beta$-Carotene from Yeasts Enhances Laccase Production of Pleurotus eryngii var. ferulae in Co-culture
}

\author{
Chaolin Guo ${ }^{1,2+}$, Liting Zhao ${ }^{1,2+}$, Feng Wang ${ }^{3}$, Jian Lu ${ }^{1,2}$, Zhongyang Ding ${ }^{1,2 *}$ and \\ Guiyang Shi
}

${ }^{1}$ Key Laboratory of Carbohydrate Chemistry and Biotechnology, Ministry of Education, School of Biotechnology, Jiangnan University, Wuxi, China, ${ }^{2}$ National Engineering Laboratory for Cereal Fermentation Technology, Jiangnan University, Wuxi, China, ${ }^{3}$ School of Food and Biological Engineering, Jiangsu University, Zhenjiang, China

\section{OPEN ACCESS}

Edited by: Dietmar Schlosser Helmholtz-Zentrum für Umweltforschung (UFZ), Germany

Reviewed by:

Montserrat Sarra, Universitat Autònoma de Barcelona, Spain

René Ullrich, Technische Universität Dresden,

Germany

*Correspondence: Zhongyang Ding bioding@163.com

tThese authors have contributed equally to this work.

Specialty section:

This article was submitted to Microbiotechnology, Ecotoxicology and Bioremediation,

a section of the journal

Frontiers in Microbiology

Received: 13 March 2017

Accepted: 31 May 2017

Published: 16 June 2017

Citation:

Guo C, Zhao L, Wang F, Lu J,

Ding Z and Shi G (2017)

$\beta$-Carotene from Yeasts Enhances Laccase Production of Pleurotus eryngii var. ferulae in Co-culture.

Front. Microbiol. 8:1101. doi: 10.3389/fmicb.2017.01101
Laccase is widely used in several industrial applications and co-culture is a common method for enhancing laccase production in submerged fermentation. In this study, the co-culture of four yeasts with Pleurotus eryngii var. ferulae was found to enhance laccase production. An analysis of sterilization temperatures and extraction conditions revealed that the stimulatory compound in yeasts was temperature-sensitive, and that it was fat-soluble. An LC-MS analysis revealed that the possible stimulatory compound for laccase production in the four yeast extracts was $\beta$-carotene. Moreover, the addition of $4 \mathrm{mg} \beta$-carotene to $150 \mathrm{~mL}$ of $P$. eryngii var. ferulae culture broth improved laccase production by 2.2 -fold compared with the control (i.e., a monoculture), and was similar to laccase production in co-culture. In addition, the enhanced laccase production was accompanied by an increase of lac gene transcription, which was 6.2-time higher than the control on the fifth day. Therefore, it was concluded that $\beta$-carotene from the co-cultured yeasts enhanced laccase production in $P$. eryngii var. ferulae, and strains that produce $\beta$-carotene could be selected to enhance fungal laccase production in a co-culture. Alternatively, $\beta$-carotene or crude extracts of $\beta$-carotene could be used to induce high laccase production in large scale.

\section{Keywords: co-culture, laccase, $\beta$-carotene, Pleurotus eryngii var. ferulae, yeast}

\section{INTRODUCTION}

Laccase (EC 1.10.3.2) is a group of blue multi-copper oxidases that are widely distributed in microorganisms, plants and insects, and capable of catalyzing the reaction various organic compounds with the reduction of oxygen. Due to its excellent activity, laccase is widely used in several applications, including dye treatment in the textile industry (Shraddha et al., 2011), pulp bleaching in the paper industry (Jeon and Chang, 2013), and in the food industry (Brijwani et al., 2010). Laccase is mainly produced by fungi, and co-culture is an effective method to optimize laccase production in submerged fermentation (Wang et al., 2009; Flores et al., 2010; Li et al., 2011).

Due to its wide application, many researchers have focused on increasing laccase production in submerged fermentation. Yeasts are hosts that are well-known to express various recombinant proteins. Therefore, some laccase-encoding genes have been isolated from fungi, 
and recombinant laccase production was effectively enhanced in yeasts (Klonowska et al., 2005; Hong et al., 2007). Besides genetic engineering technology, enhanced laccase production has also been achieved by optimizing the culture medium (Dekker et al., 2007), especially by adding inducers. Some researchers have focused on screening for effective inducers, and laccase production in Trametes versicolor has been effectively improved by farnesol and chitosan (Adekunle et al., 2015; Hu et al., 2016). Different inducers enhance laccase production by various mechanisms, including the improvement of silent or poorly expressed laccase isoforms and the response to oxidative stress caused by an inducer (Hoegger et al., 2006; Wang et al., 2014). The elucidation of these mechanisms has been beneficial to the screening of more inducers that enhance laccase production.

Currently, laccase production in white rot fungi (WRF) has been effectively enhanced with other microbial strains, including yeasts and fungi, in a co-culture fermentation (Dwivedi et al., 2011; Dong et al., 2012). Some studies have focused on the determining the mechanism of the enhancement of laccase production in a co-culture fermentation with different fungi. Yeast growth led to glucose starvation in a co-culture, which caused the overexpression of T. versicolor laccase (Wang et al., 2009). In addition, laccase production by Ganoderma lucidum may be enhanced by glycerol as a second carbon source, which was produced from glucose by the yeast in a co-culture (Li et al., 2011). Moreover, enhanced laccase production in fungi may be caused by some compounds in the culture broth of the co-cultured microbial strains (Crowe and Olsson, 2001). However, these reports did not indicate a common mechanism, and no specific compound was found to stimulate laccase production in co-culture. The discovery of unequivocal stimulatory compounds will be helpful to screen specific strains for co-culturing with fungi to improve laccase production.

In our previous study, laccase production of Pleurotus eryngii var. ferulae (Lanzi) Sacc. was significantly enhanced in a co-culture fermentation with Rhodotorula mucilaginosa (Wang et al., 2015). To determine the reason, previously reported possible mechanisms were all investigated, but none were responsible for enhanced laccase production by $P$. eryngii var. ferulae in a co-culture. In the present study, we found that the putative stimulatory compound in the co-cultured yeast was sensitive to the sterilization temperature. We then identified the stimulatory compound in the co-culture as $\beta$-carotene, and the mechanism of stimulation was also investigated.

\section{MATERIALS AND METHODS}

\section{Strains and Culture Conditions}

The laccase-producing fungus used in this study, Pleurotus eryngii var. ferulae (Lanzi) Sacc. JM301, was maintained in our laboratory on potato dextrose agar (PDA) slants at $4^{\circ} \mathrm{C}$. Four yeast strains, R. mucilaginosa, Phaffia rhodozyma, Sporidiobolus pararoseus and R. glutinis, were also maintained in our laboratory, and used in co-culture with the laccaseproducing fungi. The culture medium for P. eryngii var. ferulae was composed of: $20 \mathrm{~g} / \mathrm{L}$ glucose, $20 \mathrm{~g} / \mathrm{L}$ corn powder, $20 \mathrm{~g} / \mathrm{L}$ wheat bran and $0.1742 \mathrm{~g} / \mathrm{L} \mathrm{K}_{2} \mathrm{SO}_{4}(\mathrm{pH} 9.0)$. Fungal mycelia were inoculated in the culture medium and incubated at $30^{\circ} \mathrm{C}$ and $150 \mathrm{rpm}$. The culture medium for the yeast was YPD $(10 \mathrm{~g} / \mathrm{L}$ yeast extract, $20 \mathrm{~g} / \mathrm{L}$ peptone and $20 \mathrm{~g} / \mathrm{L}$ glucose) and cells were incubated at $30^{\circ} \mathrm{C}$ and $200 \mathrm{rpm}$.

\section{Co-culture of Laccase-Producing Fungi with Yeasts}

Inoculations were done as in our previous study, with slight modifications (Wang et al., 2015). The yeasts used in this study were cultured under the conditions described above for $48 \mathrm{~h}$, and then inoculated into a fungal culture that had been cultured for 2-days. The inoculum size of the yeast was $3 \%(\mathrm{v} / \mathrm{v})$ and the culture time was 5 days after inoculation. To investigate the effect of the sterilization temperature, $R$. mucilaginosa cells cultured for $48 \mathrm{~h}$ were exposed to different temperatures (70, $80,90,100,115$, and $\left.121^{\circ} \mathrm{C}\right)$ for $1 \mathrm{~h}$, and then $3 \%(\mathrm{v} / \mathrm{v})$ was inoculated into the monoculture of $P$. eryngii var. ferulae as above condition.

\section{Protease Treatment of $\boldsymbol{R}$. mucilaginosa}

In this study, four proteases were used to treat sterilized R. mucilaginosa cells at $70^{\circ} \mathrm{C}$. Four milligram of centrifuged cells were dissolved in $4 \mathrm{~mL}$ of distilled water and treated with four different commercial proteases, including $1 \mathrm{mg} / \mathrm{mL}$ snailase (Sangon Co., Shanghai, China) and $0.2 \mathrm{mg} / \mathrm{mL}$ pepsin (Sigma Co.), trypsase (Sangon Co.) and proteinase K (Thermal Fisher Scientific Co.). The protease treatment was carried out at $37^{\circ} \mathrm{C}$ for $5 \mathrm{~h}$. The treated cells were washed with sterilized water and collected by centrifugation twice. The centrifuged proteasetreated cells or $4 \mathrm{~g}$ of untreated cells were dissolved in $4 \mathrm{~mL}$ of sterilized water and inoculated into the fungal culture broth on day 2 .

\section{Extraction of Yeast Cells}

Rhodotorula mucilaginosa and other yeast cells were collected by centrifugation and $4 \mathrm{~g}$ of cells were dissolved in $4 \mathrm{~mL}$ of distilled water. The cells were treated eight times repetitively with freezing and thawing, then extracted with $70^{\circ} \mathrm{C}$ distilled water for $1 \mathrm{~h}$ and centrifuged at $7104 \times g$ for $10 \mathrm{~min}$. The supernatant was designated as the $\mathrm{W}$-extract of the yeast cells. Precipitates were extracted with $5 \mathrm{~mL}$ of trichloromethane at room temperature for $1 \mathrm{~h}$, and the solutions were concentrated by rotary evaporation. The extracts were dissolved in $1 \mathrm{~mL}$ of plant oil and the supernatant was designated as the O-extract of the yeast cells. The $\mathrm{W}$ - and $\mathrm{O}$-extracts of the yeast cells were added to $P$. eryngii var. ferulae under the co-culture conditions described above and the laccase activity was determined. The solvents used for the extraction were aseptically filtered.

\section{Addition of $\beta$-Carotene}

To identify the putative stimulatory compound, 1-4 mg of $\beta$-carotene of purity $\geq 96.0 \%$ (Klamar, Shanghai, China) was 
dissolved in plant oil and the solution was sterilized by aseptic filtration. Different amounts of $\beta$-carotene were added to $150-\mathrm{mL}$ of $P$. eryngii var. ferulae culture medium after $48 \mathrm{~h}$ of culture. The mycelia of $P$. eryngii var. ferulae were cultured for 5 days after the $\beta$-carotene was added, and the laccase activity in the culture broth was determined each day.

\section{LC-MS}

The four yeasts, $R$. mucilaginosa, Phaffia rhodozyma, $S$. pararoseus and R. glutinis, were co-cultured with $P$. eryngii var. ferulae. The yeast cells were collected by centrifugation and then ground in liquid nitrogen. The ground yeast cells were extracted with water and trichloromethane as mentioned above. The similar compounds in the different yeast co-cultures were separated and identified with an Ultra Performance LC system, which was connected to a Waters MALDI Q-TOF mass spectrometer (MS). Extracts of different yeasts were separated in a reverse-phase C18 column (Waters, Milford, MA, United States), and eluted with mobile phases of acetonitrileisopropanol $(10: 90, \mathrm{v} / \mathrm{v})(\mathrm{A})$ and acetonitrile (B) at flow rate of $0.3 \mathrm{~mL} / \mathrm{min}$ in a gradient program (Supplementary Table 1). The separated compounds were then detected with a MS (Waters, Milford, MA, United States). Five carotenoid standards, zeaxanthin, lycopene, astaxanthin, xanthin and $\beta$-carotene, were also assayed by the same method.

\section{Quantitative Real-Time PCR (qRT-PCR)}

Pleurotus eryngii var. ferulae mycelia cultured with $\beta$-carotene were collected by centrifugation and ground after freezing in liquid nitrogen. The mycelia were suspended in phosphate buffer ( $\mathrm{pH}$ 7.0), and the total RNA was extracted with a Trizol Total RNA Purification Kit (Sangon; Shanghai, China). Reverse transcription was carried out using a RevertAid First Strand cDNA Synthesis Kit (Fermentas; Burlington, ON, Canada) to obtain cDNA. The transcription level of lac was determined by qRT-PCR using SYBR green (TaKaRa, Japan). The primers used in this study are listed in Supplementary Table 2. The gene expression levels were normalized against the level of $r n s$, as reported previously (Li et al., 2013).

\section{Biochemical Analysis}

The laccase activity was determined according to a method reported previously (Hou et al., 2004). The 1-mL reaction mixture contained $880 \mu \mathrm{L}$ of $100 \mathrm{mM}$ sodium acetate buffer ( $\mathrm{pH} 4.5)$, ABTS solution at a final concentration of $1 \mathrm{mM}$ and $20 \mu \mathrm{L}$ of diluted enzyme solution. The laccase activity was calculated using the molar extinction coefficient of oxidized ABTS $\left(\varepsilon 420=3.6 \times 10^{4} \mathrm{M}^{-1} \mathrm{~cm}^{-1}\right)$. A unit of laccase was defined as the amount of enzyme required to oxidize $1 \mu \mathrm{mol}$ of ABTS per minute.

\section{Statistical Analysis}

All experiments were performed in triplicate and the data were expressed as the mean \pm SD. Significant differences $(p<0.05)$ between means were analyzed using GraphPad Prism 5.0 software.

\section{RESULTS}

\section{Laccase Production of $P$. eryngii var. ferulae Co-cultured with Yeast}

Our previous study indicated that the yeast $R$. mucilaginosa improved the laccase production of $P$. eryngii var. ferulae JM301 in co-culture (Wang et al., 2015). In the present study, several yeasts were co-cultured with P. eryngii var. ferulae JM301 and the laccase production was determined. The results showed that three of the yeasts, Phaffia rhodozyma, S. pararoseus and R. glutinis, significantly enhanced laccase production in co-culture, and the highest laccase production (9911 U/L) by P. eryngii var. ferulae was obtained from a co-culture with $S$. pararoseus inoculated at $3 \%$ (Figure 1). The three yeasts all had a stimulatory effect on the laccase production, which was similar to that seen with

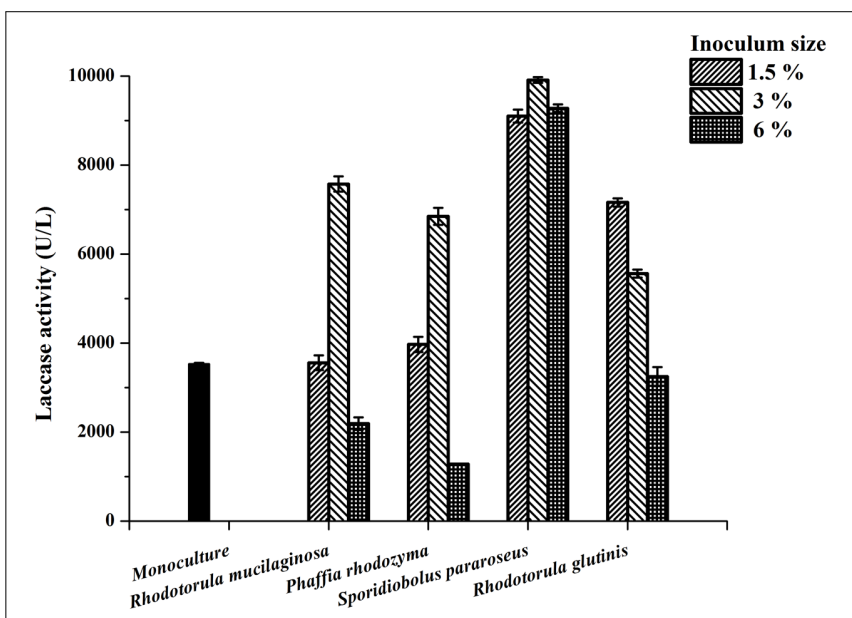

FIGURE 1 | Laccase production in co-cultures of $P$. eryngii var. ferulae and four yeasts.

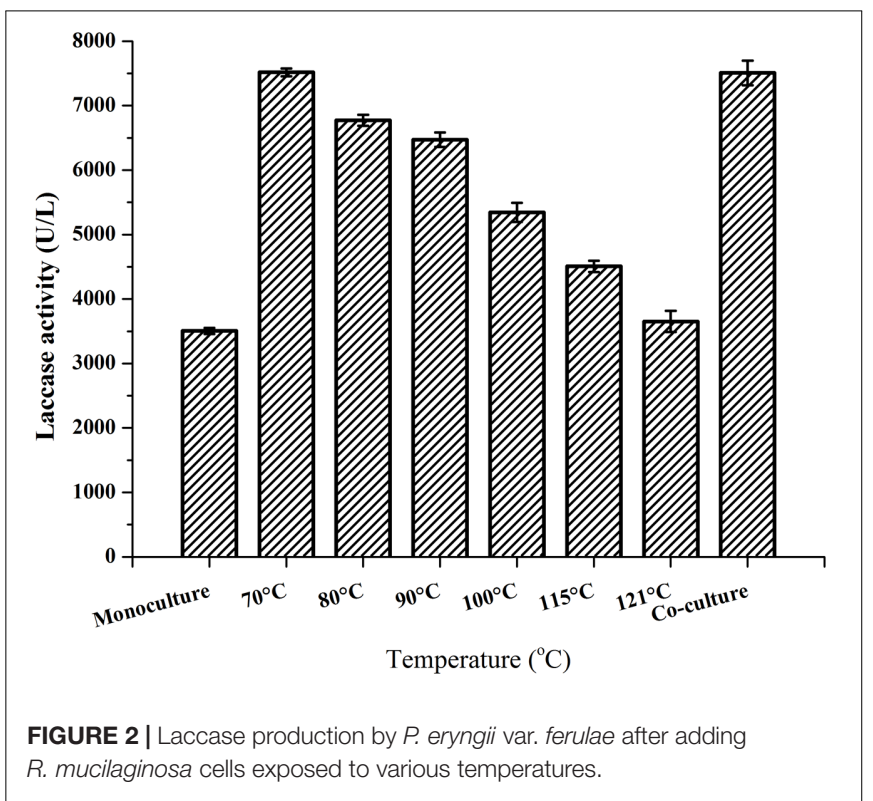




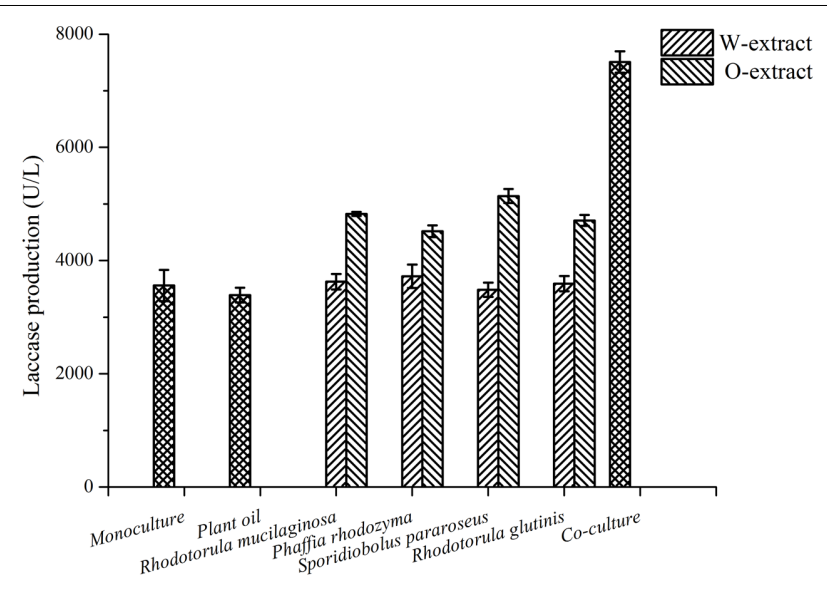

FIGURE 3 | The effect of different extractants of $R$. mucilaginosa on laccase production by $P$. eryngii var. ferulae.

R. mucilaginosa. As the inoculum size was increased from 1.5 to $6 \%$, the laccase production in co-culture peaked at $3 \%$, and was reduced at $6 \%$. Differently than for the other three yeasts, laccase production in a co-culture of $P$. eryngii var. ferulae and $R$. glutinis decreased as the inoculum size varied from 1.5 to $6 \%$.

\section{Effects of Extraction Conditions of Yeasts on Laccase Production in Co-culture}

Our previous study indicated that laccase production by $P$. eryngii var. ferulae was enhanced in a co-culture with R. mucilaginosa (Wang et al., 2015). The results of that study showed that yeast cells sterilized at $121^{\circ} \mathrm{C}$ did not improve laccase production. In the present study, we investigated the effect of various sterilization temperatures on the survival percentage of the cells. The results showed that the lowest temperature necessary for the complete sterilization of $R$. mucilaginosa was $70^{\circ} \mathrm{C}$ (Supplementary Figure 1). Moreover, the reduction of laccase production of $P$. eryngii var. ferulae was determined after adding $R$. mucilaginosa cells sterilized at temperatures that varied from 70 to $121^{\circ} \mathrm{C}$ (Figure 2). $R$. mucilaginosa cells sterilized at $121^{\circ} \mathrm{C}$ showed almost no enhancement of laccase production compared to a $P$. eryngii var. ferulae monoculture. These results indicated that the stimulatory compound existed in $R$. mucilaginosa and other yeast cells, and that this compound was temperature-sensitive.

To identify the stimulatory compounds, R. mucilaginosa cells sterilized at $70^{\circ} \mathrm{C}$ were treated with various proteases. The results showed that laccase production was not affected by any of the four protease treatments (Supplementary Figure 2). In addition, the sterilized cells were extracted with water and trichloromethane to yield different extracts of $R$. mucilaginosa cells, which were added to a culture containing $P$. eryngii var. ferulae. The trichloromethane extracts from $R$. mucilaginosa were dissolved

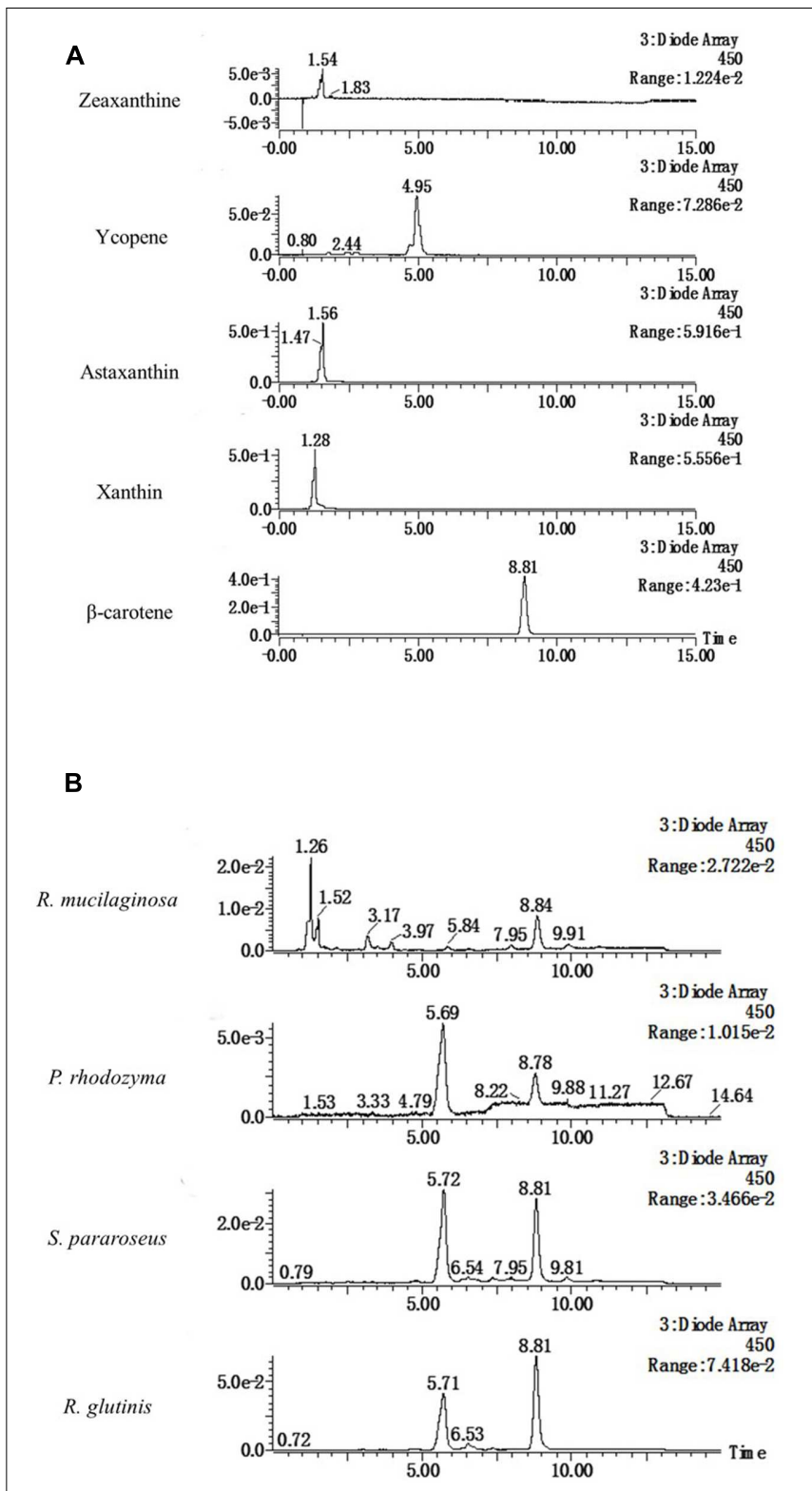

FIGURE 4 | HPLC elution profiles of (A) different carotenoid standards and (B) the tested yeasts at $450 \mathrm{~nm}$.

in plant oil (O-extract), and added to the P. eryngii var. ferulae culture broth. The results showed that the O-extract effectively enhanced laccase production to $5139 \mathrm{U} / \mathrm{L}$ by S. pararoseus (Figure 3). Therefore, the putative compound in the yeast cells was fat-soluble.

\section{LC-MS Analysis of the Stimulatory Compound in Different Yeasts}

The four yeasts used in this study all enhanced laccase production in $P$. eryngii var. ferulae in co-culture. The results from the extracts of the $R$. mucilaginosa cells led us to hypothesize that all of the yeasts used in this study contained the same 
compounds that enhanced laccase production. To investigate this compound, four yeast cells were treated with liquid nitrogen, and extracted with trichloromethane. The resultant $\mathrm{O}$-extracts from the different yeasts were analyzed by LC-MS. The results showed that all of the different yeast extracts contained the same compound, which had a retention time of $8.8 \mathrm{~min}$ (Figure 4B). Comparison with standards indicated that this compound had the same retention time as $\beta$-carotene (Figure $4 \mathbf{A}$ ). This compound was also identified as $\beta$-carotene by its MS spectrum (Figure 5).

\section{Effect of $\beta$-Carotene Addition on Laccase Production by $P$. eryngii var. ferulae}

To demonstrate that $\beta$-carotene was the stimulatory compound in yeast, 1-4 mg of $\beta$-carotene dissolved in plant oil was added to $150 \mathrm{~mL}$ of $P$. eryngii var. ferulae culture broth on day 2. After adding the $\beta$-carotene, the laccase production by $P$. eryngii var. ferulae at the end of fermentation was increased from $4351 \mathrm{U} / \mathrm{L}$ (1 $\mathrm{mg} \beta$-carotene) to $7656 \mathrm{U} / \mathrm{L}$ ( $4 \mathrm{mg} \beta$-carotene), which was higher than the laccase production in a co-culture (Figure 6). The highest laccase production after $4 \mathrm{mg} \beta$-carotene was added was 2.2-times higher than the control (i.e., a monoculture of $P$. eryngii var. ferulae). The laccase production was significantly enhanced by $\beta$-carotene, and this result indicated that the stimulatory compound in the four co-cultured yeasts was $\beta$-carotene.

\section{Transcription Level of lac in Co-culture}

The transcription level of the lac gene during submerged fermentation with or without $\beta$-carotene was determined and is shown in Figure 7 . In this experiment, $\beta$-carotene was added to the culture broth on day 2, and the laccase activity and the lac transcription level were determined on day 3. The results showed that transcription level of lac gene peaked on day 3 , and then decreased until the end of fermentation. In a monoculture of $P$. eryngii var. ferulae, the transcription of lac gene decreased sharply and remained at a low level between day 4 and day 7 (Figure 7A). In contrast, the lac transcription level after $\beta$-carotene was added was higher than the control (i.e., a monoculture) from day 3 to 6, and was 6.2-times higher than the control on day 5. Interestingly, the laccase activity of $P$. eryngii var. ferulae after $\beta$-carotene was added was higher than the control without $\beta$-carotene on day 4 (Figure 7B), and was 2.1-times higher than the control at the end of culture.

\section{DISCUSSION}

Co-culture has been an effective method to enhance laccase production in several laccase-producing fungi. In Co-culture, laccase-producing strains are always fungi, and other co-cultured strains contained yeasts and other fungi (Wang et al., 2009; Flores et al., 2010; Li et al., 2011). Possible reasons for the enhanced laccase production in a co-culture were investigated, and no clear

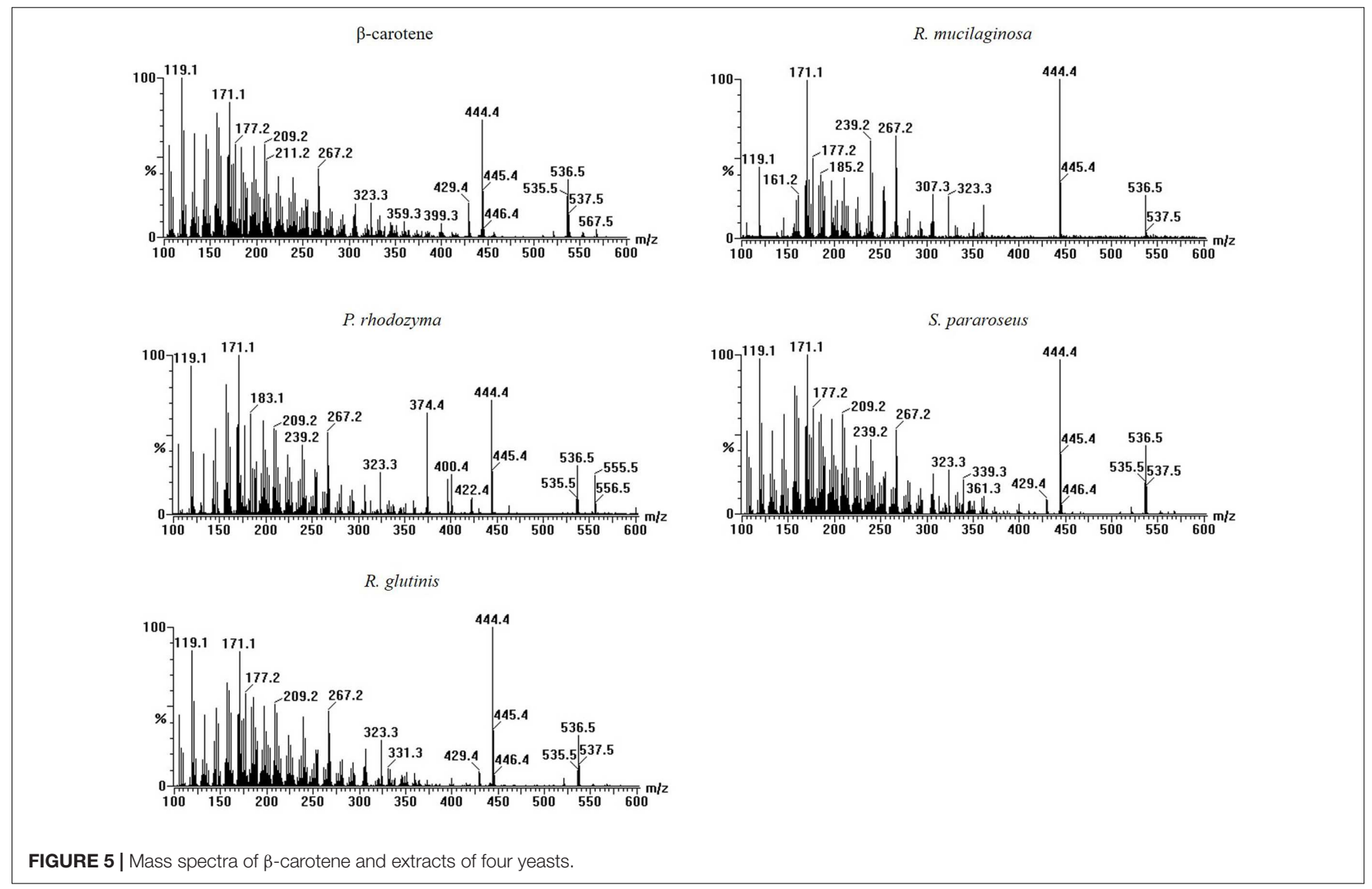




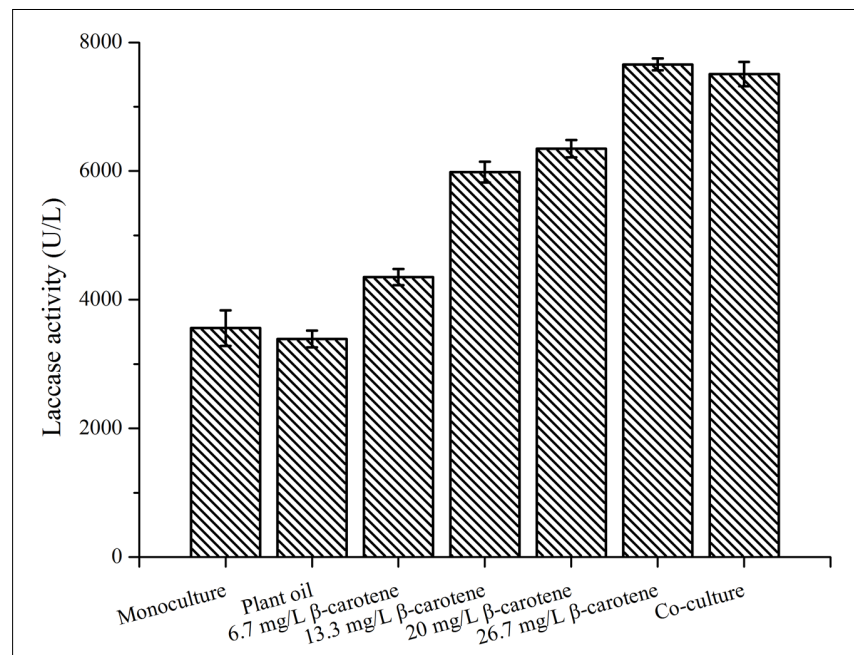

FIGURE 6 | Laccase production by P. eryngii var. ferulae after adding different concentrations of $\beta$-carotene.

mechanism for the enhancement was indicated. In our previous study, laccase production by $P$. eryngii var. ferulae was enhanced in a co-culture with the yeast $R$. mucilaginosa (Wang et al., 2015). Possible reasons reported in previous studies of other fungi did not provide a convincing explanation for the enhancement of laccase production in a co-culture of $P$. eryngii var. ferulae and $R$. mucilaginosa. Therefore, we proposed that the enhancement of laccase production might have been caused by one or several stimulatory compounds that existed in $R$. mucilaginosa cells.

In the present study, three yeasts, Phaffia rhodozyma, $S$. pararoseus and R. glutinis, were found to effectively enhance the laccase production by $P$. eryngii var. ferulae in a coculture. An analysis of sterilization temperatures indicated that the stimulatory compound in yeast was temperature-sensitive, which explained why cell extracts from $R$. mucilaginosa sterilized at $121^{\circ} \mathrm{C}$ had no effect on laccase production (Wang et al., 2015). In addition, R. mucilaginosa cells were extracted with water and trichloromethane. The compounds extracted by trichloromethane dissolved in plant oil had a positive effect on laccase production, indicating the stimulatory compound was fatsoluble. All of the yeasts tested in this study similarly improved laccase production, which led us to hypothesize that a common compound that improved laccase production was produced in co-culture. An LC-MS analysis indicated that all four yeasts contained $\beta$-carotene, which was identified by comparison with a standard. Moreover, the addition of $\beta$-carotene to a $P$. eryngii var. ferulae monoculture also improved laccase production, indicating that $\beta$-carotene in yeast was the stimulatory compound in the $P$. eryngii var. ferulae co-cultures.

$\beta$-Carotene is a carotenoid and is commonly used as a coloring agent in the food industry. Some photosynthetic organisms and microorganisms have been reported to be a primary source of carotenoids (Han et al., 2012, 2016; Srinivasan et al., 2015). Some yeasts have excellent carotenoid-producing ability, and efforts have been made to enhance carotenoid production (Shi et al., 2014; Chi et al., 2015). $\beta$-Carotene was found as an intermediate
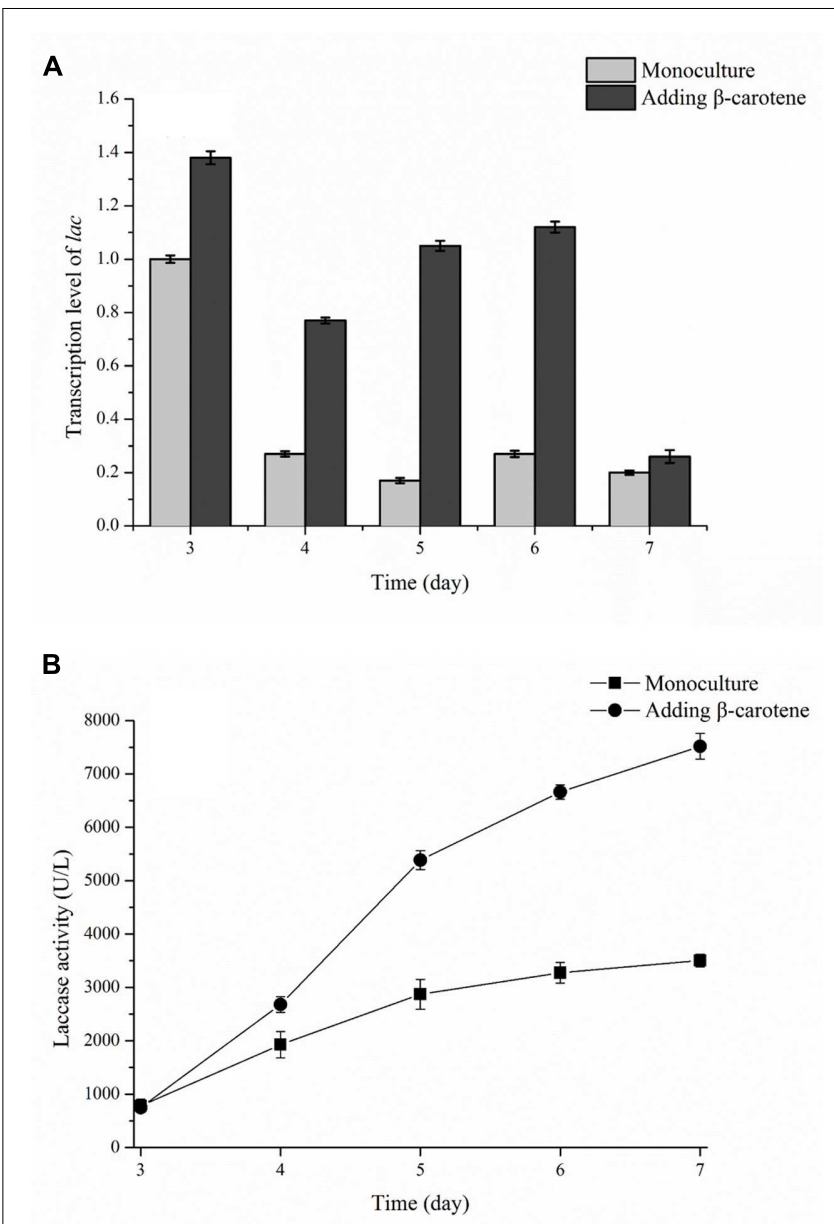

FIGURE 7 | Transcription level of the lac gene (A) and laccase production (B) in a monoculture with or without added $\beta$-carotene.

in the carotenoid synthesis pathway, and was produced from lycopene (Rodriguez-Saiz et al., 2010; Chi et al., 2015). Yeasts accumulated $\beta$-carotene and other carotenoids, allowing the yeasts to be directly used as a food additive. In the present study, $\beta$-carotene was contained in the cell extracts of all four yeasts that enhanced laccase production in co-culture, and no other carotenoids were found. The four yeasts were $R$. mucilaginosa (Moline et al., 2012), Phaffia rhodozyma (Shi et al., 2014; Chi et al., 2015), S. pararoseus (Han et al., 2012, 2016) and R. glutinis (Wang et al., 2008; Roadjanakamolson and Suntornsuk, 2010), and have been previously reported as $\beta$-carotene-producing strains. Therefore, microbial strains that accumulate $\beta$-carotene could be the primary agent that enhances laccase production by fungi in a co-culture.

Laccase is normally found in plants and fungi, and is usually produced by various fungi in submerged fermentation, taking advantage of the ease of manipulation. Various isozymes of laccase have been reported in different fungi in previous studies (Nakatani et al., 2010; Yuan et al., 2016). Hoegger et al. (2006) analyzed the genome of several fungi, and found that some fungi contained different numbers of laccase-encoding genes. 
These laccase genes were silent or poorly expressed under various culture conditions. The laccase-encoding genes contained a set of promoter regions with various recognition sites for different inducers, including metal ions and aromatic compounds (Piscitelli et al., 2011). $\beta$-Carotene is a nutrient and is also used as an antioxidant in food processing. Some oxidants have been used as inducers to enhance laccase production by fungi in submerged fermentation. Such inducers include guaiacol, ferulic acid, butylated hydroxytoluene and phenolic compounds (Kanwal and Reddy, 2011; Wang et al., 2014; Azadfar et al., 2015). Enhancement of fungal laccase production after adding an antioxidant represented a response to oxidative stress, which was caused by oxygen radicals generated by inducers (Thurston, 1994; Wang et al., 2014). A higher concentration of intracellular reactive oxygen species (ROS), including superoxide anion $\left(\mathrm{O}_{2}{ }^{-}\right)$, hydrogen peroxide $\left(\mathrm{H}_{2} \mathrm{O}_{2}\right)$ and hydroxyl radical $(\mathrm{OH}-)$, has been reported to enhance both laccase production and transcription, depending on the activation of signal transduction and the oxidative stress (Adekunle et al., 2015; Hu et al., 2016). $\mathrm{H}_{2} \mathrm{O}_{2}$ participated in the activation of the mitogen-activated protein kinase (MAPK) and cyclic adenosine monophosphate (cAMP) pathways (Calvo et al., 2002; Cap et al., 2012). Moreover, the excessive oxidative stress caused by an inducer may lead to the overexpression of laccase, which is a fungal protective response that mitigates oxidative stress (Jaszek et al., 2006). Therefore, the

\section{REFERENCES}

Adekunle, A. E., Wang, F., Hu, J., Ma, A., Guo, C., Zhuang, G., et al. (2015). Chitosan multiple addition enhances laccase production from Trametes versicolor. Bioprocess Biosyst. Eng. 38, 1973-1981. doi: 10.1007/s00449-015$1438-\mathrm{z}$

Azadfar, M., Gao, A. H., Bule, M. V., and Chen, S. (2015). Structural characterization of lignin: a potential source of antioxidants guaiacol and 4-vinylguaiacol. Int. J. Biol. Macromol. 75, 58-66. doi: 10.1016/j.ijbiomac. 2014.12.049

Brijwani, K., Rigdon, A., and Vadlani, P. V. (2010). Fungal laccases: production, function, and applications in food processing. Enzyme Res. 2010:149748. doi: 10.4061/2010/149748

Calvo, A. M., Wilson, R. A., Bok, J. W., and Keller, N. P. (2002). Relationship between secondary metabolism and fungal development. Microbiol. Mol. Biol. Rev. 66, 447-459. doi: 10.1128/MMBR.66.3.447-459.2002

Cap, M., Vachova, L., and Palkova, Z. (2012). Reactive oxygen species in the signaling and adaptation of multicellular microbial communities. Oxid. Med. Cell. Longev. 2012:976753. doi: 10.1155/2012/976753

Chi, S., He, Y., Ren, J., Su, Q., Liu, X., Chen, Z., et al. (2015). Overexpression of a bifunctional enzyme, CrtS, enhances astaxanthin synthesis through two pathways in Phaffia rhodozyma. Microbi. Cell Fact. 14:90. doi: 10.1186/s12934015-0279-4

Crowe, J. D., and Olsson, S. (2001). Induction of laccase activity in Rhizoctonia solani by antagonistic Pseudomonas fluorescens strains and a range of chemical treatments. Appl. Environ. Microbiol. 67, 2088-2094. doi: 10.1128/aem.67.5. 2088-2094.2001

Dekker, R. F., Barbosa, A. M., Giese, E. C., Godoy, S. D., and Covizzi, L. G. (2007). Influence of nutrients on enhancing laccase production by Botryosphaeria rhodina MAMB-05. Int. Microbiol. 10, 177-185. doi: 10.2436/20.1501. 01.25

Dong, Y. C., Wang, W., Hu, Z. C., Fu, M. L., and Chen, Q. H. (2012). The synergistic effect on production of lignin-modifying enzymes through submerged co-cultivation of Phlebia radiata, Dichomitus squalens and Ceriporiopsis subvermispora using agricultural residues. Bioprocess Biosyst. Eng. 35, 751-760. doi: 10.1007/s00449-011-0655-3 $\beta$-carotene in the co-cultured yeasts in this study may enhance laccase production by changing intracellular ROS concentration.

\section{AUTHOR CONTRIBUTIONS}

CG and ZD designed experiments. CG and LZ performed the experiments. FW, JL, ZD, and GS conceived the project, analyzed data, and wrote the paper.

\section{FUNDING}

Funding support for this study was provided by the National Natural Science Foundation of China (31571822) and Fundamental Research Funds for the Central Universities (JUSRP51615B). This study was also sponsored by the Qing Lan Project.

\section{SUPPLEMENTARY MATERIAL}

The Supplementary Material for this article can be found online at: http://journal.frontiersin.org/article/10.3389/fmicb. 2017.01101/full\#supplementary-material

Dwivedi, P., Vivekanand, V., Pareek, N., Sharma, A., and Singh, R. P. (2011). Co-cultivation of mutant Penicillium oxalicum SAU(E)-3.510 and Pleurotus ostreatus for simultaneous biosynthesis of xylanase and laccase under solidstate fermentation. N. Biotechnol. 28, 616-626. doi: 10.1016/j.nbt.2011. 05.006

Flores, C., Casasanero, R., Trejo-Hernandez, M. R., Galindo, E., and SerranoCarreon, L. (2010). Production of laccases by Pleurotus ostreatus in submerged fermentation in co-culture with Trichoderma viride. J. Appl. Microbiol. 108, 810-817. doi: 10.1111/j.1365-2672.2009.04493.x

Han, M., He, Q., and Zhang, W. G. (2012). Carotenoids production in different culture conditions by Sporidiobolus pararoseus. Prep. Biochem. Biotechnol. 42, 293-303. doi: 10.1080/10826068.2011.583974

Han, M., Xu, Z. Y., Du, C., Qian, H., and Zhang, W. G. (2016). Effects of nitrogen on the lipid and carotenoid accumulation of oleaginous yeast Sporidiobolus pararoseus. Bioprocess Biosyst. Eng. 39, 1425-1433. doi: 10.1007/s00449-0161620-y

Hoegger, P. J., Kilaru, S., James, T. Y., Thacker, J. R., and Kues, U. (2006). Phylogenetic comparison and classification of laccase and related multicopper oxidase protein sequences. FEBS J. 273, 2308-2326. doi: 10.1111/j.1742-4658. 2006.05247.x

Hong, Y. Z., Zhou, H. M., Tu, X. M., Li, J. F., and Xiao, Y. Z. (2007). Cloning of a laccase gene from a novel basidiomycete Trametes sp. 420 and its heterologous expression in Pichia pastoris. Curr. Microbiol. 54, 260-265. doi: 10.1007/s00284006-0068-8

Hou, H. M., Zhou, J. T., Wang, J., Du, C. H., and Yan, B. (2004). Enhancement of laccase production by Pleurotus ostreatus and its use for the decolorization of anthraquinone dye. Process Biochem. 39, 1415-1419. doi: 10.1016/s00329592(03)00267-x

Hu, J., Wang, F., Ma, A., Zhuang, G., Liu, Y., Lu, J., et al. (2016). Farnesol stimulates laccase production in Trametes versicolor. Eng. Life Sci. 16, 364-370. doi: 10.1002/elsc.201500082

Jaszek, M., Grzywnowicz, K., Malarczyk, E., and Leonowicz, A. (2006). Enhanced extracellular laccase activity as a part of the response system of white rot fungi: Trametes versicolor and Abortiporus biennis to paraquat-caused oxidative stress conditions. Pestic. Biochem. Physiol. 85, 147-154. doi: 10.1016/j.pestbp.2006. 01.002 
Jeon, J. R., and Chang, Y. S. (2013). Laccase-mediated oxidation of small organics: bifunctional roles for versatile applications. Trends Biotechnol. 31, 335-341. doi: 10.1016/j.tibtech.2013.04.002

Kanwal, H. K., and Reddy, M. S. (2011). Effect of carbon, nitrogen sources and inducers on ligninolytic enzyme production by Morchella crassipes. World J. Microbiol. Biotechnol. 27, 687-691. doi: 10.1007/s11274-010-0507-3

Klonowska, A., Gaudin, C., Asso, M., Fournel, A., Reglier, M., and Tron, T. (2005). LAC3, a new low redox potential laccase from Trametes sp. strain C30 obtained as a recombinant protein in yeast. Enzyme Microb. Technol. 36, 34-41. doi: 10.1016/j.enzmictec.2004.03.022

Li, J., Zhang, J., Chen, H., Chen, X., Lan, J., and Liu, C. (2013). Complete mitochondrial genome of the medicinal mushroom Ganoderma lucidum. PLoS ONE 8:e72038. doi: 10.1371/journal.pone.0072038

Li, P., Wang, H. L., Liu, G. S., Li, X., and Yao, J. M. (2011). The effect of carbon source succession on laccase activity in the co-culture process of Ganoderma lucidum and a yeast. Enzyme Microb. Technol. 48, 1-6. doi: 10.1016/j.enzmictec. 2010.07.005

Moline, M., Libkind, D., and van Broock, M. (2012). Production of torularhodin, torulene, and beta-carotene by Rhodotorula yeasts. Methods Mol. Biol. 898, 275-283. doi: 10.1007/978-1-61779-918-1_19

Nakatani, M., Hibi, M., Minoda, M., Ogawa, J., Yokozeki, K., and Shimizu, S. (2010). Two laccase isoenzymes and a peroxidase of a commercial laccaseproducing basidiomycete, Trametes sp. Hal. N. Biotechnol. 27, 317-323. doi: 10.1016/j.nbt.2010.02.008

Piscitelli, A., Giardina, P., Lettera, V., Pezzella, C., Sannia, G., and Faraco, V. (2011). Induction and transcriptional regulation of laccases in fungi. Curr. Genomics 12, 104-112. doi: 10.2174/138920211795564331

Roadjanakamolson, M., and Suntornsuk, W. (2010). Production of beta-caroteneenriched rice bran using solid-state fermentation of Rhodotorula glutinis. J. Microbiol. Biotechnol. 20, 525-531. doi: 10.4014/jmb.0809.0550

Rodriguez-Saiz, M., de la Fuente, J. L., and Barredo, J. L. (2010). Xanthophyllomyces dendrorhous for the industrial production of astaxanthin. Appl. Microbiol. Biotechnol. 88, 645-658. doi: 10.1007/s00253-010-2814-X

Shi, F., Zhan, W., Li, Y., and Wang, X. (2014). Temperature influences betacarotene production in recombinant Saccharomyces cerevisiae expressing carotenogenic genes from Phaffia rhodozyma. World J. Microbiol. Biotechnol. 30, 125-133. doi: 10.1007/s11274-013-1428-8
Shraddha, Shekher, R., Sehgal, S., Kamthania, M., and Kumar, A. (2011). Laccase: microbial sources, production, purification, and potential biotechnological applications. Enzyme Res. 2011:217861. doi: 10.4061/2011/217861

Srinivasan, R., Kumar, V. A., Kumar, D., Ramesh, N., Babu, S., and Gothandam, K. M. (2015). Effect of dissolved inorganic carbon on beta-carotene and fatty acid production in Dunaliella sp. Appl. Biochem. Biotechnol. 175, 2895-2906. doi: 10.1007/s12010-014-1461-6

Thurston, C. F. (1994). The structure and function of fungal laccases. Microbiology 140, 19-26. doi: 10.1099/13500872-140-1- 19

Wang, F., Hu, J.-H., Guo, C., and Liu, C.-Z. (2014). Enhanced laccase production by Trametes versicolor using corn steep liquor as both nitrogen source and inducer. Bioresour. Technol. 166, 602-605. doi: 10.1016/j.biortech.2014.05.068

Wang, H., Peng, L., Ding, Z., Wu, J., and Shi, G. (2015). Stimulated laccase production of Pleurotus ferulae JM301 fungus by Rhodotorula mucilaginosa yeast in co-culture. Process Biochem. 50, 901-905. doi: 10.1016/j.procbio.2015. 03.004

Wang, H. L., Yu, G. L., Li, P., Gu, Y. C., Li, J., Liu, G. S., et al. (2009). Overproduction of Trametes versicolor laccase by making glucose starvation using yeast. Enzyme Microb. Technol. 45, 146-149. doi: 10.1016/j.enzmictec. 2009.04.003

Wang, S. L., Chen, D. J., Deng, B. W., and Wu, X. Z. (2008). Effects of high hydrostatic pressure on the growth and beta-carotene production of Rhodotorula glutinis. Yeast 25, 251-257. doi: 10.1002/yea.1583

Yuan, X., Tian, G., Zhao, Y., Zhao, L., Wang, H., and Ng, T. B. (2016). Biochemical characteristics of three laccase isoforms from the basidiomycete Pleurotus nebrodensis. Molecules 21:E203. doi: 10.3390/molecules21020203

Conflict of Interest Statement: The authors declare that the research was conducted in the absence of any commercial or financial relationships that could be construed as a potential conflict of interest.

Copyright (c) 2017 Guo, Zhao, Wang, Lu, Ding and Shi. This is an open-access article distributed under the terms of the Creative Commons Attribution License (CC BY). The use, distribution or reproduction in other forums is permitted, provided the original author(s) or licensor are credited and that the original publication in this journal is cited, in accordance with accepted academic practice. No use, distribution or reproduction is permitted which does not comply with these terms. 